\title{
Lycopene-rich fractions derived from pink guava by-product and their potential activity towards hydrogen peroxide-induced cellular and DNA damage.
}

\begin{abstract}
Effects of solvent and supercritical carbon dioxide (SC-CO2) extraction on antioxidant and cytotoxic activities of lycopene-rich fractions of decanted pink guava by-product (decanter) were determined with lycopene-equivalent antioxidant capacity, $\beta$-carotene bleaching and MTT (3-(4,5-dimethylthiazol-2yl)-2,5-diphenyl tetrazolium bromide) assays. Extraction with SC-CO2 gave a higher yield than solvent extraction $(3.15$ vs. $0.68 \mathrm{mg} / 100 \mathrm{~g}$ dried decanter, corresponding to 42.99 and $33.63 \mathrm{mg}$ of lycopene). No cytotoxicity was found in Chang liver cells supplemented with either extracts $(6.25-200 \mu \mathrm{g} / \mathrm{ml})$. Solvent extract at $25 \mu \mathrm{g} / \mathrm{ml}(2.32 \mu \mathrm{M}$ lycopene) and SC-CO2 extract at $200 \mu \mathrm{g} / \mathrm{ml}(5.09 \mu \mathrm{M}$ lycopene) had protective effect against hydrogen peroxide-induced cytotoxicity. However, only high concentrations of solvent extract $(200 \mu \mathrm{g} / \mathrm{ml}$; lycopene $=18.65 \mu \mathrm{M})$ or lycopene standard $(10 \mu \mathrm{M})$ protected cells against DNA damage. Supercritical fluid extraction demonstrated a higher yield in lycopene-rich fraction from decanter. These fractions have the potential to be developed as a functional ingredient to prevent oxidative stress and other related diseases.
\end{abstract}

Keyword: By-product; Comet assay; Cytotoxicity; DNA damage; Lycopene; Psidium guajava. 